\title{
UV SPECTROPHOTOMETRY METHOD DEVELOPMENT AND VALIDATION OF SULFADIAZINE AND TRIMETHOPRIM IN COMBINED DOSAGE FORM
}

\author{
RAMAKRISHNA VENI POKALA ${ }^{*}$, KUSUMA KUMARI², HARI BABU BOLLIKOLA ${ }^{3}$
}

${ }^{1}$ Department of Applied Sciences and Humanities, Sasi Institute of Technology \& Engineering, Tadepalligudem 534101, Andhra Pradesh, India, ${ }^{2}$ Department of Chemistry, Andhra Christian College, Guntur 522002, Andhra Pradesh, India, ${ }^{3}$ Department of Chemistry, Acharya

Nagarjuna University, Nagarjuna Nagar, Guntur 522510, Andhra Pradesh, India

Email: prk.veni@gmail.com

Received: 02 Aug 2017 Revised and Accepted: 22 Nov 2017

\section{ABSTRACT}

Objective: A new, simple, sensitive and economical UV spectrophotometric method was developed for the simultaneous analysis of Sulfadiazine [SDA] and Trimethoprim [TMP] in pharmaceutical formulations.

Methods: This UV method was developed with methanol as solvent. The wavelengths selected for analysis in the present method were $265 \mathrm{~nm}$ for TMP and $289 \mathrm{~nm}$ for SDA. Teccomp UV-2301 double beam UV/Vis spectrophotometer was used to carry out spectral analysis and the data was recorded by Hitachi software.

Results: Linearity was found to be within the concentration range of 2-9 $\mu \mathrm{g} / \mathrm{ml}$ TMP and $9.08-41 \mu \mathrm{g} / \mathrm{ml}$ of SDA. Accuracy of the method was determined by recovery studies. Percentage recovery was found to be $98.20-99.25$ for TMP with a $\%$ RSD of $0.338,0.506$ and 0.510 for three spiked levels. \% RSD was found to be 0.229 and $0.380 ; 0.212$ and 0.328 for SDA, TMP in intra and inter-day precision respectively. The \% RSD value in ruggedness was found to be 0.440 for SDA and 0.569 for TMP.

Conclusion: The advantages of this method for analytical purposes lie in the rapid determination, its cost-effectiveness, easy preparation of the sample, good reproducibility. In addition to this, the present method can be recommended for simultaneous determination of SDA and TMP in routine quality control analysis in combined drug formulations.

Keywords: Sulfadiazine, Trimethoprim, UV-Method and Methanol

(C) 2018 The Authors. Published by Innovare Academic Sciences Pvt Ltd. This is an open access article under the CC BY license (http://creativecommons.org/licenses/by/4.0/) DOI: http://dx.doi.org/10.22159/ijpps.2018v10i1.21767

\section{INTRODUCTION}

SDA is a sulfonamide antibiotic and synthetic bacteriostatic with a wide spectrum against most gram-positive and many gram-negative organisms. This compound belongs to the aminobenzene sulfonamides [1]. The medication was used to treat and prevent a wide variety of infections. It works by stopping the growth of bacteria and other organisms. SDA was used as a competitive inhibitor of the bacterial enzyme dihydropteroate synthetase [2]. This enzyme is needed for the proper processing of paraaminobenzoic acid which is essential for folic acid synthesis. The inhibited reaction is necessary in these organisms for the synthesis of folic acid [3]. This antibiotic treats only certain types of infections. It will not work for viral infections e. g., common cold, flu, nausea, vomiting, diarrhea, loss of appetite, and headaches are the side effects of SDA.

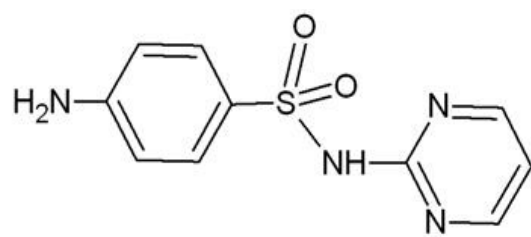

Fig. 1: Chemical structure of SDA [6]

TMP is on the World Health Organization's List of Essential Medicines [4]. TMP is a bacteriostatic antibiotic used mainly in the prevention and treatment of urinary tract infections. The drug belongs to the class of chemotherapeutic agents known as dihydrofolate reductase inhibitors. It is primarily used in the treatment of urinary tract infections, although it may be used against any susceptible aerobic bacterial species [5]. It was also used to treat and prevent Pneumocystis jiroveci pneumonia. TMP inhibits production of tetrahydrofolic acid by inhibiting the enzyme responsible for making tetrahydrofolic acid from dihydrofolic acid. TMP has an affinity for bacterial dihydrofolate reductase and has several thousand times greater than its affinity for human dihydrofolate reductase. TMP inhibits the bacterial enzyme more than the human enzyme.<smiles>COc1cc(Cc2cnc(N)nc2N)cc(OC)c1OC</smiles>

Fig. 2: Chemical structure of TMP [16]

Literature survey reveals that only a few selected spectrophotometric [6-8], HPLC [10-11], and HPLC-LC-MS [18], methods were reported for the estimation of SDA and TMP individually, UVVisible [9], HPLC [12-17], as a combination with other drugs in bulk and biological samples. There are two HPLC [19-20], one stability indicating HPLC [21], and four LC-MS [22-25] methods for the estimation of SDA and TMP as a combination in bulk and biological 
samples. However to the best of the knowledge of the author no spectrophotometric method was developed for the estimation of this combination. Hence in the present investigation, an attempt was made to develop a simple, sensitive and economical UV/Vis spectrophotometric method for the simultaneous analysis of SDA and TMP in pharmaceutical formulations.

\section{MATERIALS AND METHODS}

\section{Instrumentation}

Teccomp UV-2301 double beam UV/Vis spectrophotometer was used to carry out spectral analysis and the data was recorded by Hitachi software. Standard cuvettes of $10 \mathrm{~mm}$ path length are used for analysis. Sonicator $(1.3 \mathrm{~L})$ ultrasonicator was used to sonicate the standard and formulation sample. Standard and sample drugs were weighed by using Denver electronic analytical balance (SI234).

\section{Chemicals and reagents}

The reference sample of SDA and TMP was a kind gift of Hetro Pharma, Hyderabad and Lupin Ltd, Mumbai, India, respectively. The formulation AUBRIL (SDA-410 mg and TMP-90 mg) was purchased from local market. Methanol (solvent) of analytical grade was purchased from Merck specialties Private Limited, Mumbai, India.

\section{Preparation of standard drug solution}

$10 \mathrm{mg}$ of standard drug SDA and TMP was accurately weighed separately and dissolved in $5 \mathrm{ml}$ diluent (methanol), then transferred into a $10 \mathrm{ml}$ volumetric flask, sonicated it for $5 \mathrm{~min}$, finally, volume was made up to the mark with the same solvent to make $1000 \mu \mathrm{g} / \mathrm{ml}$ stock solution. From this $1 \mathrm{ml}$ was again diluted to $10 \mathrm{ml}$ to get a concentration of $100 \mu \mathrm{g} / \mathrm{ml}$ solution of TMP and SDA, separately. Then the required concentration was prepared separately, $1 \mathrm{ml}$ from each of these solutions were mixed to obtain a combined solution for the simultaneous estimation of TMP and SDA.

\section{Selection of method and wavelength}

The standard stock solution was further diluted with milli-Q water to obtain the concentration of $10 \mu \mathrm{g} / \mathrm{ml}$, each solution was scanned in UV range [200-400 nm] in $1.0 \mathrm{~cm}$ cell against solvent blank. The overlain spectrum of drugs was recorded. The study of spectrum revealed that SDA and TMP show a well-defined $\lambda \max$ individually. The spectra of overlay for the two drugs confirmed that TMP at 265 $\mathrm{nm}$ and SDA at $289 \mathrm{~nm}$ were found to be suitable $\lambda \max$ for the selected drugs. The obtained wavelength maxima for the two drugs were used for the simultaneous estimation of SDA and TMP using simultaneous equation method. The wavelength scanning overlay spectrum was given in fig. 3 .

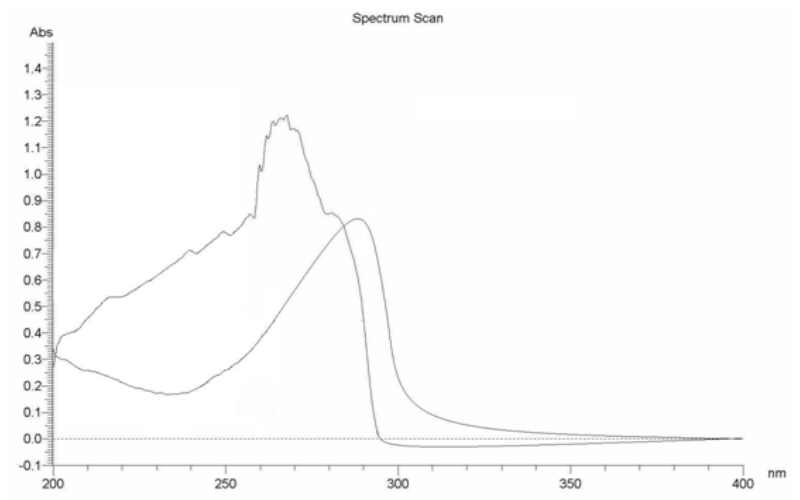

Fig. 3: Overlay spectrum of SDA and TMP

\section{RESULTS}

The method was validated as per ICH guidelines [26].

\section{Linearity}

Linear relationship between absorbance and concentration of the drugs was evaluated over the concentration range expressed in $\mu \mathrm{g} / \mathrm{ml}$ by making three replicate measurements in the concentration range of 2-9 $\mu \mathrm{g} / \mathrm{ml}$ TMP and 9.08-41 $\mu \mathrm{g} / \mathrm{ml}$ of SDA at the wavelength maxima of TMP at $265 \mathrm{~nm}$ and SDA at $289 \mathrm{~nm}$ for each of the drugs. The calibration curve was drawn using absorbance obtained against concentration prepared separately for both the drugs. A well correlated linear fit graph was observed for both the drugs in the concentration range studied. Linearity results were shown in table 1 and graphs were given in fig. 4 and fig. 5 for TMP and SDA, respectively.

Table 1: Linearity results for SDA and TMP

\begin{tabular}{lllll}
\hline S. No. & TMP & & SDA & Absorbance \\
\cline { 2 - 5 } & Concentration & Absorbance & Concentration & $0.362 \pm 0.002$ \\
\hline 1 & $2 \mu \mathrm{g} / \mathrm{ml}$ & $0.229 \pm 0.002$ & $9.08 \mu \mathrm{g} / \mathrm{ml}$ & $0.487 \pm 0.005$ \\
2 & $3 \mu \mathrm{g} / \mathrm{ml}$ & $0.325 \pm 0.004$ & $13.64 \mu \mathrm{g} / \mathrm{ml}$ & $0.639 \pm 0.003$ \\
3 & $4 \mu \mathrm{g} / \mathrm{ml}$ & $0.451 \pm 0.002$ & $18.2 \mu \mathrm{g} / \mathrm{ml}$ & $0.787 \pm 0.001$ \\
4 & $5 \mu \mathrm{gl}$ & $0.566 \pm 0.002$ & $22.76 \mu \mathrm{g} / \mathrm{ml}$ & $0.925 \pm 0.003$ \\
5 & $6 \mu \mathrm{gl} / \mathrm{ml}$ & $0.665 \pm 0.001$ & $27.32 \mu \mathrm{g} / \mathrm{ml}$ & $1.058 \pm 0.002$ \\
6 & $7 \mu \mathrm{gl}$ & $0.751 \pm 0.001$ & $31.88 \mu \mathrm{g} / \mathrm{ml}$ & $1.221 \pm 0.002$ \\
7 & $8 \mu \mathrm{g} / \mathrm{ml}$ & $0.869 \pm 0.004$ & $36.44 \mu \mathrm{g} / \mathrm{ml}$ & $1.345 \pm 0.005$ \\
8 & $9 \mu \mathrm{ml}$ & $0.988 \pm 0.004$ & $41.00 \mu \mathrm{g} / \mathrm{ml}$ & 0.0312 \\
& Slope & 0.1075 & Slope & 0.0721 \\
& Intercept & 0.0141 & Intercept & 0.9995 \\
\hline
\end{tabular}

*values given in table are the average \pm standard deviation of three replicate experiments

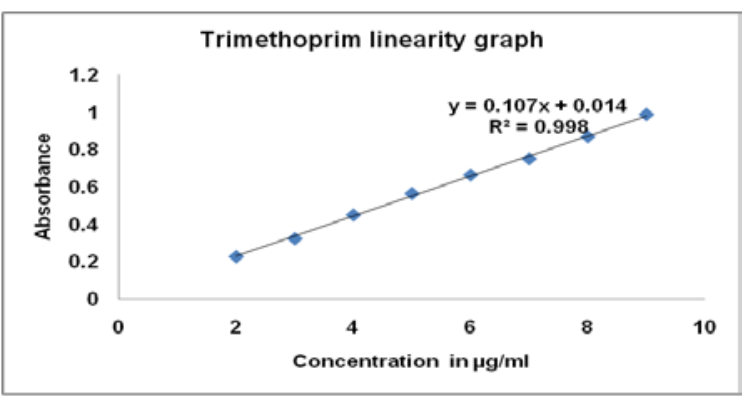

Fig. 4: Linearity graph for TMP 


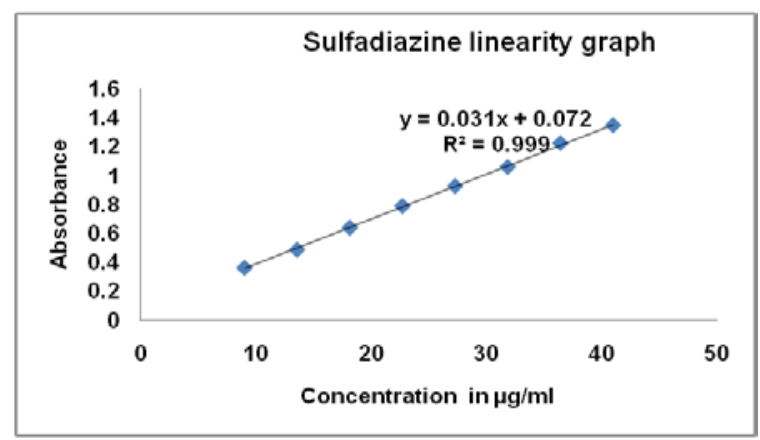

Fig. 5: Linearity graph for SDA

\section{Recovery}

Recovery studies were performed by standard addition method. The accuracy of the method was ascertained by carrying out recovery studies at three different levels $(50 \%, 100 \%$ and $150 \%)$. The resultant solution was analyzed in their corresponding wavelength.
Using the absorbance values obtained, percentage recovery and RSD in each spiked level were calculated. Results were found to be within the acceptance limit of 98-102 and percentage RSD of less than 2 .

This confirms that the proposed method was found to be accurate. Results of the recovery were given in table 2 for SDA and TMP.

Table 2: Recovery results for SDA and TMP

\begin{tabular}{lllllll}
\hline Drug & \% of recovery & Target conc., $[\boldsymbol{\mu g} / \mathbf{m l}]$ & $\begin{array}{l}\text { Spiked conc., } \\
{[\boldsymbol{\mu g} / \mathbf{m l}]}\end{array}$ & $\begin{array}{l}\text { Final conc., } \\
{[\boldsymbol{\mu g} / \mathbf{m l}]}\end{array}$ & $\begin{array}{l}\text { Conc., } \\
\text { obtained }[\boldsymbol{\mu g} / \mathbf{m l}]\end{array}$ & $\begin{array}{l}\text { \% recovery } \\
\text { RSD of recovery }\end{array}$ \\
\hline SDA & $50 \%$ & 9.08 & 4.54 & 13.62 & $13.553 \pm 0.031$ & $99.510 \pm 0.229$ \\
& $100 \%$ & 9.08 & 9.08 & 18.16 & $18.113 \pm 0.035$ & 0.225 \\
& $150 \%$ & 9.08 & 13.62 & 31.78 & $22.533 \pm 0.078$ & $99.740 \pm 0.191$ \\
TMP & $50 \%$ & 2 & 1 & 3 & $2.960 \pm 0.010$ & $98.667 \pm 0.343$ \\
& $100 \%$ & 2 & 2 & 4 & $3.950 \pm 0.020$ & 0.345 \\
& $150 \%$ & 2 & 3 & 5 & $4.937 \pm 0.025$ & $98.750 \pm 0.500$ \\
\hline
\end{tabular}

*values given in table are the average \pm standard deviation of three replicate experiments

\section{Precision}

Repeatability and intermediate precision of the developed method were expressed in terms of relative standard deviation of the absorbance. The sample application and measurement of absorbance were determined by performing six replicates measurement of the same band using a sample solution containing SDA at $41 \mu \mathrm{g} / \mathrm{ml}$ and TMP at $9 \mu \mathrm{g} / \mathrm{ml}$. The solution was analyzed six replicates in the same day for intra-day precision and three successive days for inter-day precision. Percentage RSD was found to be 0.229 and 0.380 for SDA; 0.212 and 0.328 for TMP in intra and inter-day precision, respectively.

Results confirmed that the precision of the method was found to be accepted. Precision results were given in table 3 and table 4 for intra and inter-day precision respectively.

Table 3: Intra-day precision results for SDA and TMP

\begin{tabular}{lll}
\hline S. No. & TMP at $\mathbf{~} \boldsymbol{\mu g} / \mathbf{m l}$ & SDA at $\mathbf{4 1} \boldsymbol{\mu g} / \mathbf{m l}$ \\
\hline 1 & 0.988 & 1.345 \\
2 & 0.986 & 1.341 \\
3 & 0.987 & 1.349 \\
4 & 0.987 & 1.341 \\
5 & 0.986 & 1.344 \\
6 & 0.982 & 1.342 \\
RSD & 0.212 & 0.229 \\
\hline
\end{tabular}

Table 4: Inter-day precision results for SDA and TMP

\begin{tabular}{lll}
\hline S. No. & TMP at $\mathbf{9} \boldsymbol{\mu g} / \mathbf{m l}$ & SDA at $\mathbf{4 1} \boldsymbol{\mu g} / \mathbf{m l}$ \\
\hline 1 & 0.989 & 1.338 \\
2 & 0.987 & 1.334 \\
3 & 0.989 & 1.334 \\
4 & 0.991 & 1.339 \\
5 & 0.996 & 1.346 \\
6 & 0.993 & 1.332 \\
RSD & 0.328 & 0.380 \\
\hline
\end{tabular}

\section{Ruggedness}

The ruggedness was performed by analyzing the drug solution using the same system but with different analysts. The difference between two analysts was compared using percentage RSD values. The percentage RSD value was found to be 0.440 for SDA and 0.569 for TMP in six replicates of absorbance.

The low percentage RSD value illustrates the ruggedness of the method. Table 5 gives the results of the Ruggedness. 
Table 5: Ruggedness results for SDA and TMP

\begin{tabular}{lll}
\hline S. No. & TMP at $\mathbf{9} \boldsymbol{\mu g} / \mathbf{m l}$ & SDA at $\mathbf{4 1} \boldsymbol{\mu g} / \mathbf{m l}$ \\
\hline 1 & 0.986 & 1.344 \\
2 & 0.999 & 1.349 \\
3 & 0.997 & 1.332 \\
4 & 0.988 & 1.339 \\
5 & 0.986 & 1.345 \\
6 & 0.992 & 1.344 \\
RSD & 0.569 & 0.440 \\
\hline
\end{tabular}

\section{Sensitivity of the method}

The sensitivity of the developed method was expressed in terms of the limit of detection [LOD] and limit of quantification [LOQ] values. The combined standard solution was prepared and the absorbance of the prepared solution was measured, at decreasing concentrations. The LOD values were found to be $0.04 \mu \mathrm{g} / \mathrm{ml}$ for TMP and $0.13 \mu \mathrm{g} / \mathrm{ml}$ for SDA in the optimized method.

This confirmed that the method can be applicable at lowest concentration for both the drugs. The LOQ values were found to be 0.82 $\mu \mathrm{g} / \mathrm{ml}$ for SDA and $0.25 \mu \mathrm{g} / \mathrm{ml}$ for TMP. Results were given in table 6 .

Table 6: Sensitivity results for SDA and TMP

\begin{tabular}{lll}
\hline Drug & LOQ & LOD \\
\hline Trimethoprim & $0.04 \mu \mathrm{g} / \mathrm{ml}$ & $0.25 \mu \mathrm{g} / \mathrm{ml}$ \\
Sulfadiazine & $0.13 \mu \mathrm{g} / \mathrm{ml}$ & $0.82 \mu \mathrm{g} / \mathrm{ml}$ \\
\hline
\end{tabular}

\section{Formulation analysis}

The tablet sample solution was also subjected to analysis by simultaneous equation method. The absorbance of sample solutions were recorded at $265 \mathrm{~nm}$ and $289 \mathrm{~nm}$ and concentration of two drugs in the sample were determined by using equations 1 and 2 .

Equation 1: Simultaneous equation for the estimation of TMP

$C_{x}=A_{2} a_{y 1}-A_{1} a_{y 2} / a_{x 2} a_{y 1}-a_{x 1} a_{y 2}$

Equation 2: Simultaneous equation for the estimation of SDA

$C_{y}=A_{1} a_{x 2}-A_{2} a_{x 1} / a_{x 2} a_{y 1}-a_{x 1} a_{y 2}$

Where:

$\mathrm{ax}_{1}=$ Absorptivity of TMP at $265 \mathrm{~nm}$ $\mathrm{ax}_{2}=$ Absorptivity of TMP at $289 \mathrm{~nm}$

ay $_{1}=$ Absorptivity of SDA at $265 \mathrm{~nm}$

ay $_{2}=$ Absorptivity of SDA at $289 \mathrm{~nm}$

$A_{1}$ and $A_{2}$ are the absorbances of the diluted sample at $265 \mathrm{~nm}$ and $289 \mathrm{~nm}$ respectively.

Results of the formulation analysis confirmed that the method can estimate more than $98 \%$ accurately and the results were found to be in good agreement to the label claim values. The \% assay was found to be 98.96 for SDA and 99.40 for TMP.

This confirmed that the method was found to be suitable for the routine analysis of SDA and TMP in pharmaceutical formulations. The results of the formulation analysis were given in table 7 .

Table7: Formulation results for SDA and TMP

\begin{tabular}{llllll}
\hline S. No. & Drug & Brand name & Label claim & Amount prepared & Amount found [ $\boldsymbol{\mu g} / \mathbf{m l}]$ \\
\hline 1 & TMP & AUBRIL & $90 \mathrm{mg}$ & $9 \mu \mathrm{g} / \mathrm{ml}$ assay & $8.946 \pm 0.021$ \\
2 & SDA & & $410 \mathrm{mg}$ & $41 \mu \mathrm{g} / \mathrm{ml}$ & $40.573 \pm 0.094$ \\
\hline
\end{tabular}

*values given in table are the average \pm standard deviation of three replicate experiments

\section{DISCUSSION}

A simultaneous equation UV spectrophotometric method was developed and validated as per ICH guidelines [26] for the simultaneous estimation of SDA and TMP in tablet dosage form. The solvent used was $50 \% v / v$ aqueous methanol. The absorbance was recorded at $265 \mathrm{~nm}$ and $289 \mathrm{~nm}$. The overlain spectrum was shown in fig. 3.

The absorbance at TMP at $265 \mathrm{~nm}$ and SDA at $289 \mathrm{~nm}$ were measured and calibration curves were plotted. The absorptive values were determined with both the wavelengths in the mixture. The absorbance and absorptive values at particular wavelength were calculated and substituted in the equation to obtain the concentration. Linearity was found to be within the concentration range of 2-9 $\mu \mathrm{g} / \mathrm{ml} \mathrm{TMP}$ and $9.08-41 \mu \mathrm{g} / \mathrm{ml}$ of SDA.

The accuracy of the method was determined by recovery studies. Percentage recovery was found to be $98.20-99.25$ for TMP with a \% RSD of $0.338,0.506$ and 0.510 for three spiked levels. Results were found to be within the accepted limit of 98-102 and percentage RSD of less than 2. This confirmed that the proposed method was found to be accurate. Repeatability of the method was studied by precision experiments. \% RSD was found to be 0.229 and $0.380 ; 0.212$ and 0.328 for SDA, TMP in intra and inter-day precision respectively. The $\%$ RSD value in ruggedness was found to be 0.440 for SDA and 0.569 [table 5] for TMP in six replicates of absorbance. The low percentage RSD value illustrates the ruggedness of the method.

The proposed methods were found to be simple, accurate and rapid for the routine determination of SDA and TMP in tablet formulation. To study the validity and reproducibility of proposed methods, recovery studies were carried out. The methods were validated in terms of linearity, accuracy, precision, specificity and reproducibility.

\section{CONCLUSION}

A simultaneous equation UV spectrophotometry method was developed and validated as per ICH (International Conference on Harmonization) guidelines for the determination of SDA and TMP in combined dosage forms using methanol as solvent. The advantages of the proposed method for analytical purposes lie in the rapid determination, cost-effectiveness, easy preparation of the sample, 
good reproducibility, simple, economic, accurate and practical. Hence, the proposed method can be recommended for simultaneous determination of SDA and TMP in routine quality control analysis in combined drug formulations.

\section{AUTHOR'S CONTRIBUTION}

The present work was done in collaboration with the three authors, Rama Krishna Veni, Kusuma Kumari and Hari Babu. Author Rama Krishna Veni is involved in conducting the experiments, collection of literature and preparation of the manuscript. Data analyzing and manuscript corrections were done by authors Kusuma Kumari and Hari Babu.

\section{CONFLICT OF INTERESTS}

Declared none

\section{REFERENCES}

1. De Araujo MV, Vieira EK, Silva Lazaro G, Conegero LS, Almeida LE, Barreto LS, et al. Sulfadiazine/Hydroxypropyl-beta-cyclodextrin host-guest system: characterization, phase-solubility and molecular modeling. Bioorg Med Chem 2008;16:5788-94.

2. Iliades P, Meshnick SR, Macreadie IG. Dihydropteroate synthase mutations in Pneumocystis Jiroveciican affect sulfamethoxazole resistance in a Saccharomyces Cerevisiae model. Antimicrob Agents Chemother 2005;49:741-8.

3. Prabhu V, Lui H, King J. Arabidopsis dihydropteroate synthase: general properties and inhibition by reaction product and sulfonamides. Phytochemistry 1997;45:23-7.

4. "WHO model list of essential medicines" World Health Organization October, Retrieved; 2014.

5. Rossi S. The Australian Medicines Handbook Unit Trust; 2013.

6. Vandana K, Arun Kumar D, Umadevi K, Shiva KT, Harika L, Kishant Kumar P. Method development and validation of sulphadiazine in bulk and pharmaceutical dosage form by UV-spectrophotometric method. Int J Pharm Biol Arch 2011;2:1167-71.

7. Salim AM, Haseeb YSZ. Spectrophotometric determination of sulfadiazine via diazotization and coupling reaction-application to pharmaceutical preparations. Raf J Sci 2013;24:61-73.

8. Goran S, Elizabeta DS, Marija S, Romel V. Optimization, validation and application of UV-Vis spectrophotometriccolourimetric methods for determination of trimethoprim in different medicinal products. Mac Vet Rev 2016;39:65-76.

9. Shamsa F, Amani L. Determination of sulfamethoxazole and trimethoprim in pharmaceuticals by visible and UV spectrophotometry. Iran J Pharm Res 2006;1:31-6.

10. Behzadian NG, Rezaee A, Kebriaeezadeh A. High-performance liquid chromatographic determination of trimethoprim in mouse liver. Pharm Pharmacol Commun 1998;4:439-41.

11. Nordholm L, Dalgard LA. Assay of trimethoprim in plasma and urine by high-performance liquid chromatography. J Chromatogr 1982;233:427-31.

12. Springolo V, Coppi G. HPLC determination of tetroxoprim and sulphadiazine in pharmaceutical dosage forms and in biological fluids. J Pharm Biomed Anal 1989;7:57-65.

13. Goulas V, Anisimova AT, Angastinioti MC, Tzamaloukas O. A rapid HPLC method for the determination of sulphonamides and trimethoprim in feed premixes. J Anim Feed Sci 2014;23:185-9.

14. Mashhour G, Saleh AL. Development and validation of an RPHPLC method for the simultaneous determination of trimethoprim, sulfadimidine sodium and tylosin tartrate in an injectable solution formulation. J Appl Pharm Sci 2015;5:94-8.

15. Abbas R, Qorban BN, Abbas K. Simultaneous analysis of trimethoprim and sulphamethoxazole drug combinations in dosage forms by high-performance liquid chromatography. Iran Biomed J 2000;4:75-8.

16. Gurumurthy T, Monika M, Ashwini V. Development and validation RP-HPLC method for simultaneous estimation of sulfamethoxazole and trimethoprim. Indian J Res Pharm Biotechnol 2017;5:235-8.

17. Bonazzi D, Anddrisano V, Di Pietra AM, Cavrini V. Analysis of trimethoprim--sulfonamide drug combinations in dosage forms by UV spectroscopy and liquid chromatography (HPLC). Farmaco 1994;49:381-6.

18. Nachilobe P, Cassidy RM, Fesser ACE. Determination of trimethoprim in bovine serum high-performance liquid chromatography with confirmation by thermospray liquid chromathography-mass spectrometry. J Chromathogr 1993;616:243-52.

19. Gentleman MS, Burt HM, Kitts DD, McErlane KM. Highperformance liquid chromatographic determination of sulphadiazine and trimethoprim in chinook salmon muscle tissue. J Chromatogr A 1993;633:105-10.

20. Batzias GC, Botsoglou NA, Kotsaki-Kovatsi VP, Kounenis G. New simple liquid chromatographic method for the determination of trimethoprim, sulfadiazine and n4-acetylsulfadiazine in plasma of broilers. J Chromatogr B Anal Technol Biomed Life Sci 2002;769:253-9.

21. Mashhour MG, Saleh AA. Development and validation of a stability-indicating HPLC method for the simultaneous determination of sulfadiazine sodium and trimethoprim in injectable solution formulation. Sci Pharm 2013;81:167-82.

22. Baere SD, Baert K, Croubels S, Busser JD, Wasch K, Backer PD. Determination and quantification of sulfadiazine and trimethoprim in swine tissues using liquid chromatography with ultraviolet and mass spectrometric detection. Analyst 2000;125:409-15.

23. Croubels S, Pascal W, Backer PD. Simultaneous determination of sulfadiazine and trimethoprim in animal feed by liquid chromatography with $\mathrm{UV}$ and tandem mass spectrometric detection. Anal Chim Acta 2002;473:183-94.

24. Croubels S, Baere SD, Backer PD. Comparison of a liquid chromatographic method with ultraviolet and ion-trap tandem mass spectrometric detection for the simultaneous determination of sulfadiazine and trimethoprim in plasma from dogs. J Chromatogr B 2003;788:167-78.

25. Sorensen LK, Elbaek TH. Simultaneous determination of trimethoprim, sulfadiazine, florfenicol and oxolinic acid in surface water by liquid chromatography-tandem mass spectrometry. Chromatographia 2004;60:287-91.

26. International Conference of Harmonization. Validation of Analytical Procedures: Text and Methodology. Geneva, Switzerland: ICH Q2 (R1); 2005. 